\title{
Climate Sensitivity to Land Use Changes over the City of Brussels
}

\author{
Gwenn Cugnon ${ }^{\mathrm{A}}$, Steven Caluwaerts ${ }^{\mathrm{B}}$, François Duchêne ${ }^{\mathrm{A}}$, Rafiq Hamdi ${ }^{\mathrm{A}}$, Piet Termonia ${ }^{\mathrm{A}} \mathrm{B}$, \\ Sara Top ${ }^{B, C}$, Thomas Vergauwen ${ }^{B}$, Bert Van Schaeybroeck ${ }^{A^{*}}$ \\ Received: November 27, 2019 | Revised: December 25, 2019 | Accepted: December 26, 2019 \\ DOI: $10.5937 / g p 23-24214$
}

\begin{abstract}
Prompted with the ongoing and projected climate change, a wide range of cities have committed, not only to mitigate greenhouse gas emissions but also to implement different climate change adaptation measures. These measures serve to ensure the wellbeing of the urban population. In practice, however, the planning of realistic adaptation measures is a complex process. Prior to starting such endeavor, it may therefore be useful to explore the maximum potential benefit that can be gained through adaptation measures. In this work, simple, extreme yet realistic adaptation measures are proposed in terms of changes in albedo and vegetation fraction. The impact of these land-use scenarios is explored by use of the land surface model SURFEX on the summer climate in terms of heat waves and the urban heat island for the city of Brussels. This is done for different periods in the future using the greenhouse gas scenario RCP8.5.
\end{abstract}

Keywords: climate change; adaptation; land use; urban climatology; scenarios

\section{Introduction}

Impacts on society of the ongoing global warming are already apparent, for instance through the increase of extreme events (Masson-Delmotte et al., 2018). The European heat wave in 2003 , for example, resulted in an excess mortality of 70.000 deaths (Robine et al. 2008). The increase in average temperature over most European regions exceeds the one of the global average and this is projected to continue (Jacob et al., 2018). Additionally, heat waves will become longer and more intense (Jacob et al., 2014; Guerreiro et al., 2018). Among all weather-related hazards, heat waves are projected to have the largest impact on human lives over Europe (Forzieri et al., 2017). In cities, temperature extremes are known to be stronger given the
Urban Heat Island (UHI) i.e. the phenomenon where the average temperature within the city is higher than the surrounding countryside (Rosenzweig et al., 2018). The UHI is also often found to be more intense during heat waves (Zhou \& Shepherd, 2010; for Brussels see Hamdi et al., 2016) and is largest at night. This leads to elevated health risks as the high night-time temperatures prevent people in an urban environment to recover from the intense day-time heat stress. For Belgium, which has a high degree of urbanization (See Map 3.4C in EEA 2016), climate-change impacts for the urban environment have been studied in Wouters et al. (2016), for the city of Antwerp in Martinez et al. (2018) and for Brussels in Hamdi et al. (2014, 2015,

\footnotetext{
A Royal Meteorological Institute of Belgium, Brussels, Ringlaan 3, 1180 Brussels, Belgium; gwcugnon@hotmail.com, francois. duchene@meteo.be, rafiq.hamdi@meteo.be, termonia@meteo.be, bertvs@meteo.be

B Department of Physics and Astronomy, Ghent University, S9, Krijgslaan 281, 9000 Ghent, Belgium; steven.caluwaerts@UGent. be, thomas.vergauwen@UGent.be

c Department of Geography, Ghent University, Ghent University, S8, Krijgslaan 281, 9000 Ghent, Belgium, Sara.Top@UGent.be

* Corresponding author: Bert Van Schaeybroeck; e-mail: bertvs@meteo.be
} 
2016) and Lauwaet et al. (2016). Moreover, urban monitoring networks to investigate the urban climatology have recently been established in the city of Ghent (Caluwaerts et al., 2019).

The signing of the Paris Agreement has fostered the engagement of cities worldwide to introduce sustainable climate-resilient solutions and to organize themselves in city action groups (see Annex 1.1 in Rosenzweig et al., 2018). For instance, in Europe around 10.000 local authorities have signed the Covenant of Mayors. Thereby they actively adopt an integrated approach to climate change and are required to develop concrete plans for Sustainable Energy and Climate Action.

The establishment of practical adaptation measures for cities, however, requires an interactive and itera- tive co-development with multiple city actors from different sectors and is therefore very complicated (e.g. Masson et al, 2013, Rosenzweig et al., 2018). It is therefore worthwhile to estimate beforehand the potential gain of different adaptation measures. To this aim, two types of model experiments are proposed here: one vegetation and one albedo experiment. Their impact on the local summer climate and during heat waves are explored for different periods in the future following the greenhouse gas scenario RCP8.5. In practice a change of albedo in urban areas can be established by a change of the building and roof colors (Oleson et al, 2010). The vegetation scenario, on the other hand, can be implemented by the widespread introduction of parks and trees (Rosenzweig et al., 2018; De Munck et al., 2018).

\section{Data and Methods}

\section{Climate data generation}

Climate projections over Brussels have been performed with a horizontal resolution of $1-\mathrm{km}$. Therefore the land surface model SURFEX (SURface Externalisée) was used in off-line mode forced with atmospheric forcing data from the regional climate model ALARO-o (Termonia et al, 2018a). This forcing data with $4-\mathrm{km}$ resolution spans a period from 1976 until 2100 following the greenhouse concentrations of the IPCC scenario RCP8.5 (Termonia et al., 2018b). This simulation was obtained by dynamically downscaling the ALARO-o simulations over the European (EURO-CORDEX) domain, as validated in Giot et al. (2015).

The presented land-use scenarios were implemented in the last downscaling step to $1-\mathrm{km}$ resolution using SURFEX that includes four surface types (nature, city, sea and lake) within each grid box and associated physics parameterization schemes. The city parameterization scheme is the Town Energy Balance (TEB) model which is an urban canopy model (Masson, 2000). The unperturbed land-use coverage is taken from the global ECOCLIMAP database (Masson et al., 2003) for a region of $30 \mathrm{~km}$ by $30 \mathrm{~km}$ over Brussels (see Figure 1). The accuracy of this dataset and its impact on the simulation of the urban climatology was recently explored in Top et al. (2019) for the city of Ghent. Further details of the specific downscaling setup can be found in Termonia et al. (2018c) and Helsen et al. (2019).

Comparable downscaling efforts with SURFEX over Belgium were performed and validated in Hamdi et al. (2015) for Brussels and in Caluwaerts et al. (2019) for Ghent. The current setup, however, does not use daily restarts of the ALARO-o model and SURFEX is not coupled inline to the $(4-\mathrm{km})$ ALARO model. As shown in
Hamdi et al. (2014) the lack of this atmosphere-city coupling results in an underestimation of the UHI effect.

Although the climate simulations span the time period 1976-2100, the analysis will focus on the period 2010-2100 only by comparing the impact between different land-use scenarios.

\section{Land-use scenarios}

Prior to introducing the land-use scenarios it is important to consider the unperturbed land use characteristics over Brussels as shown in Figure 1. The different land-use types are reduced to three major categories: dense urban, sub-urban and rural tiles. The first two correspond to the 17 dark-red ("dense urban") and 250 light-pink ("temperate sub-urban") tiles in Figure 1, respectively. The rural tiles comprise the last six tile types in the caption of Figure 1.

The scenarios presented further only target the urban and sub-urban tiles and all results are averages over the concerned tiles. Their main characteristics (impermeable fraction, vegetation fraction and building heights) are tabulated in Table 1. The first experiment involves a change in albedo in the urban and sub-urban regions while the second vegetation scenario introduces a modified fraction of vegetation in the dense urban environment only.

Table 1. Land-use characteristics of the dense urban and sub-urban tiles

\begin{tabular}{|l|c|c|}
\hline Land-use feature & Dense Urban tiles & Sub-urban tiles \\
\hline $\begin{array}{l}\text { Impermeable } \\
\text { surfaces }\end{array}$ & $90 \%$ & $50 \%$ \\
\hline Vegetation & $10 \%$ & $50 \%$ \\
\hline Building height & $30 \mathrm{~m}$ & $10 \mathrm{~m}$ \\
\hline
\end{tabular}




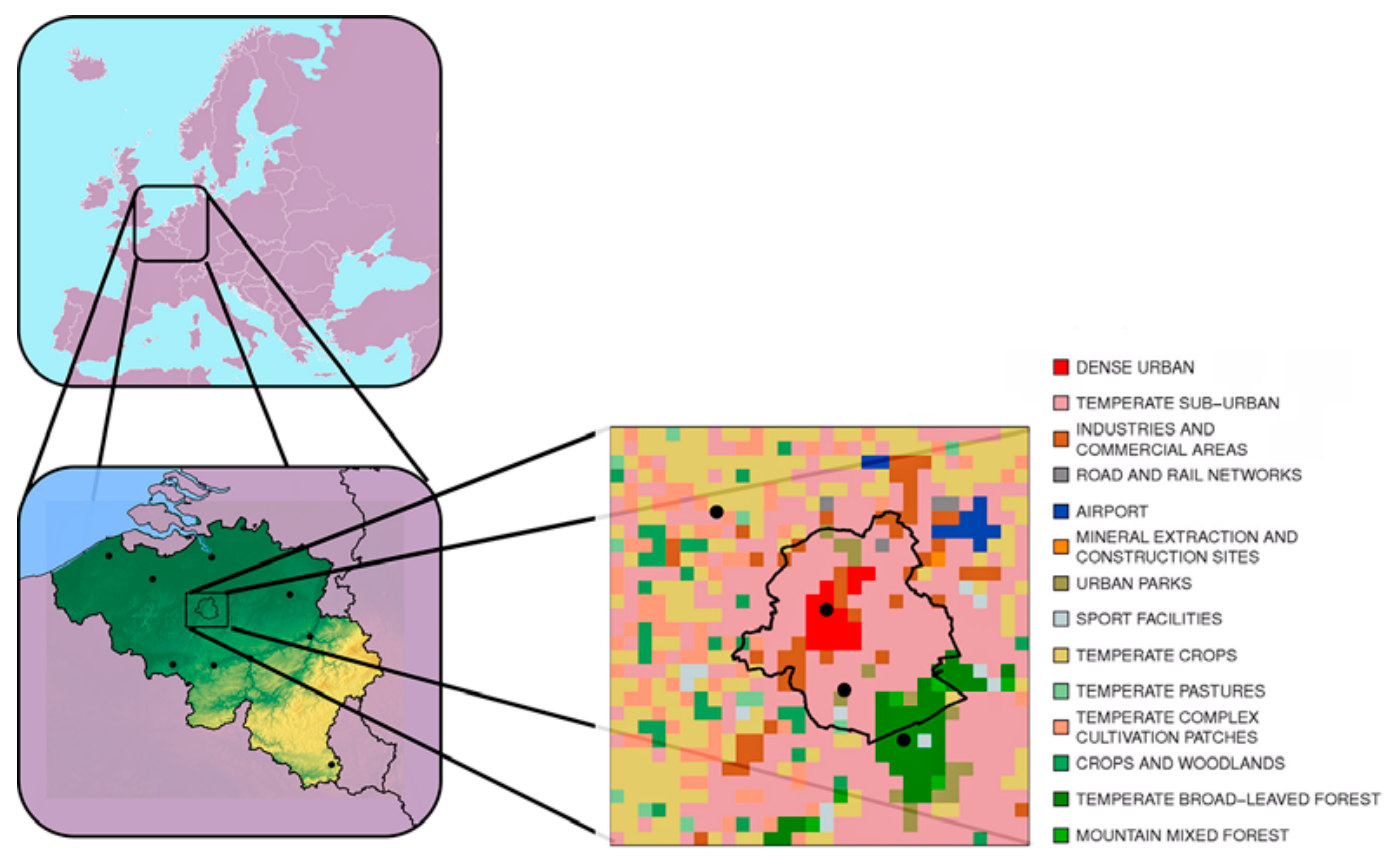

Figure 1. Downscaling methodology for the city of Brussels and land-use characteristics at 1-km scale as used for the climate runs within SURFEX in the urban scenarios (right figure taken from Hamdi et al., 2016). See Map 3.4c in EEA (2016) for degree of urbanization in and around Belgium

\section{Albedo scenario}

The albedo scenario involves a change in albedo of streets, walls and roofs that are used in the impermeable surfaces for both the urban and sub-urban regions. The default or unperturbed albedo values are $8 \%, 25 \%$ and $15 \%$ for streets, walls and roofs, respectively. In Table 2 we tabulate the values used for the three scenarios: Albedo min, Albedo av and Albedo max. The maximal values (around $80 \%$ ) are extreme but still realistic. As aforementioned, these extreme values are chosen to probe the sensitivity of the UHI with respect to changes in the land-use characteristics.

\section{Vegetation scenarios}

While the vegetation fraction of the unperturbed dense urban tiles is by default $10 \%$, two vegetation scenarios are proposed with increased fraction. More specifically the FractVeg 0.3 and FractVeg 0.5 scenarios increase the fraction to $30 \%$ and $50 \%$, respectively as tabulated in Table 3.
Table 2. The albedo in the SURFEX model for the street, walls and roofs for the different albedo scenarios

\begin{tabular}{|l|c|c|c|}
\hline $\begin{array}{l}\text { Albedo } \\
\text { experiment }\end{array}$ & Streets & Walls & Roofs \\
\hline Initial & $8 \%$ & $25 \%$ & $15 \%$ \\
\hline Albedo min & $20 \%$ & $40 \%$ & $25 \%$ \\
\hline Albedo av & $50 \%$ & $62 \%$ & $55 \%$ \\
\hline Albedo max & $80 \%$ & $85 \%$ & $85 \%$ \\
\hline
\end{tabular}

Table 3. The vegetation fraction of the dense urban tiles for the default configuration and two vegetation scenarios

\begin{tabular}{|l|c|}
\hline Vegetation experiment & $\begin{array}{c}\text { Vegetation fraction dense } \\
\text { urban tiles }\end{array}$ \\
\hline Initial & $10 \%$ \\
\hline FractVeg 0.3 & $30 \%$ \\
\hline FractVeg 0.5 & $50 \%$ \\
\hline
\end{tabular}

\section{Results}

\section{Results of the reference runs}

Figure 2 shows the increase in the average yearly temperature for the urban, sub-urban and rural environment of Brussels for the years 2010-210o following the RCP 8.5 scenario. The overall temperature increase of $3^{\circ} \mathrm{C}$ to $4^{\circ} \mathrm{C}$ for this scenario is in line with projections from global, regional and other local downscaling efforts (Termonia et al., 2018c). Average temperatures in the dense urban environment are systematically higher than those in the sub-urban areas which, in turn, systematically exceed those in the rural areas. This shows the existence in the model of the ob- 


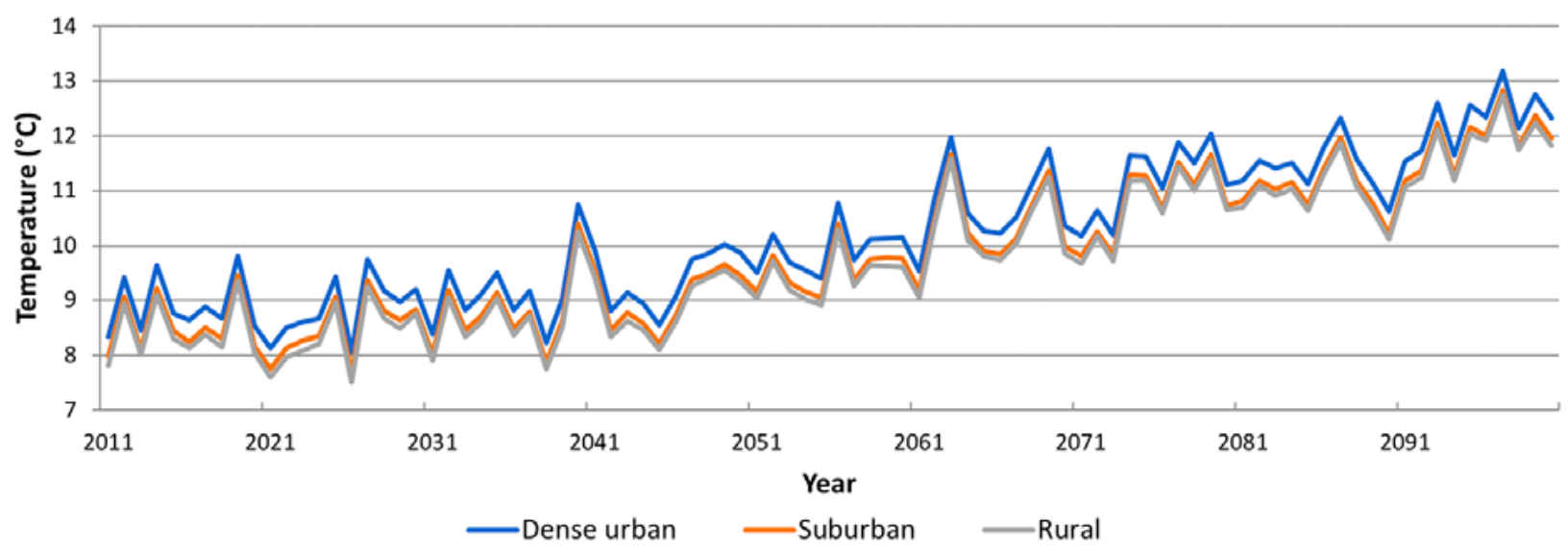

Figure 2. Average yearly temperature for rural (grey), sub-urban (orange) and dense urban (blue) locations over Brussels for the years 2010-2100 following the greenhouse gas scenario RCP8.5

served urban heat island effect over Brussels (Hamdi et al., 2014).

The summer temperature difference of the dense urban and sub-urban environment with the rural area is shown in Figure 3 for three periods: 2010-2040, 2040-2070 and 2070-2100. It is clear that the differences among the different periods are very small and similar findings appear when studying the different adaptation scenarios. The invariance of the UHI with respect to the time period might, however, be a consequence of lack of two-way urban-atmosphere coupling in the SURFEX forcing data (Hamdi et al., 2014).
There is, on the other hand a marked difference in the UHI between the dense urban and the sub-urban region, especially at night.

For the heat wave in this work, we use the definition from the Belgian Public Health authorities. According to this definition, a heat wave is a period of at least three consecutive days, with an average daily minimum and maximum temperatures that exceed $18^{\circ} \mathrm{C}$ and $30^{\circ} \mathrm{C}$, respectively. The constraint on the minimal temperature in this health-related definition stems from the fact that people suffer most from heat waves featuring high night-time temperatures.

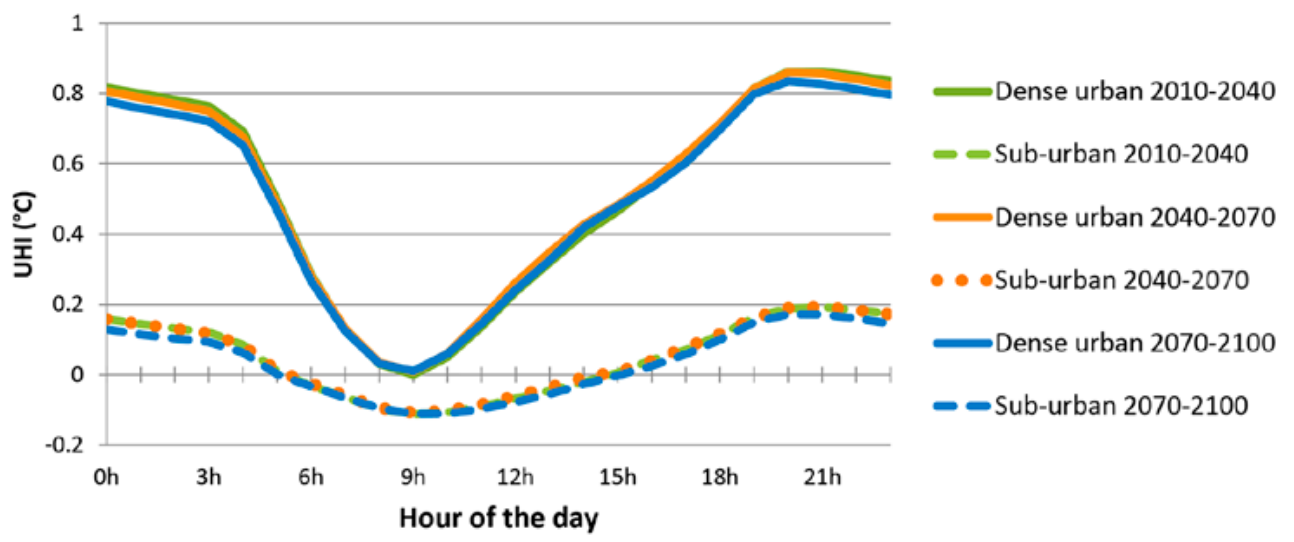

Figure 3. Diurnal cycle (hours UTC) of the summer Urban Heat Island (UHI). The UHI is obtained by subtracting the temperature of the dense urban (full line) or sub-urban (dashes and dots) environment with the temperature of the rural environment

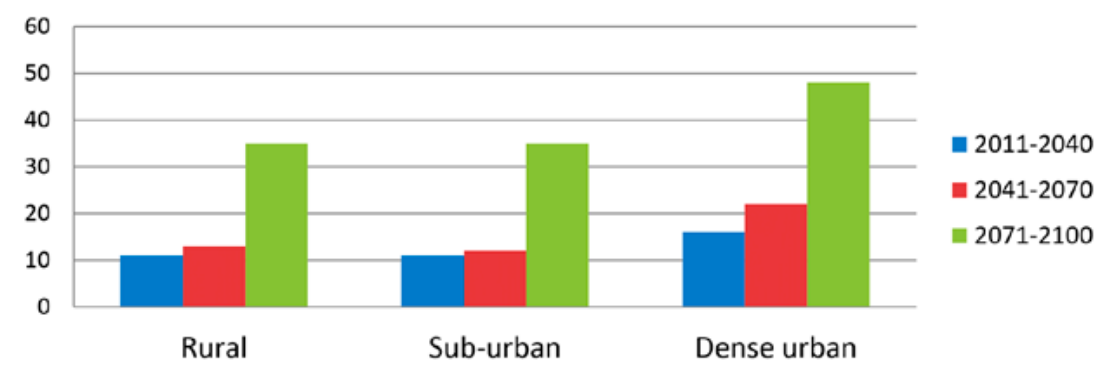

Figure 4. The number of heat waves for the three land-use types and for the periods 2010-2040, 2040-2070 and 2070-2100 following the RCP8.5 scenario 
In line with the overall increase in temperature until the end of the century as shown in Figure 2, there is also a strong increase in the number of heat waves, especially in the period 2070-2100. This is shown in Figure 4 for the dense urban, sub-urban and rural areas.

\section{Results for the Albedo scenarios}

Figure 5 shows the impact of the albedo increase of the dense urban and sub-urban environment on the diurnal cycle of the summer UHI for the urban and

\section{Results for the Vegetation scenario}

While a change in albedo mostly affects the day-time UHI in the perturbed dense urban environment, the opposite is true for the increase in vegetation fraction. As seen in Figure 6, there is a strong reduction in the night-time UHI of $0.47^{\circ} \mathrm{C}$ following the VegFraction 0.5 scenario and only a slight UHI increase during day time. The reduction of the night-time UHI is logical given that, after greening, the dense urban tiles will more strongly resemble the rural tiles.

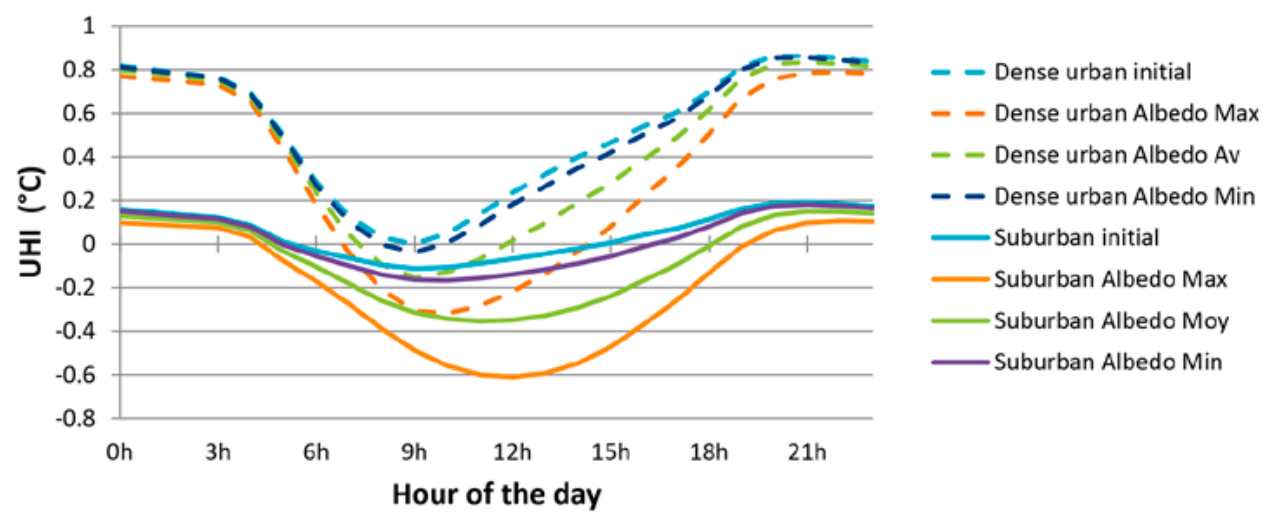

Figure 5. Diurnal cycle (hours UTC) of the summer Urban Heat Island (UHI) for different albedo scenarios for the period 2010-2040

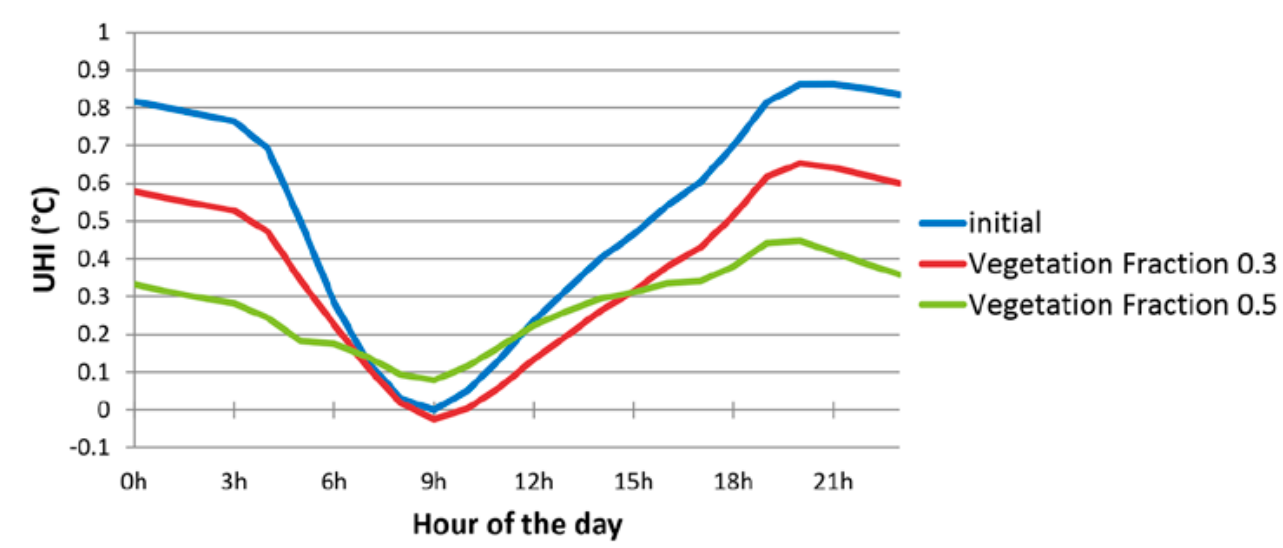

Figure 6. Diurnal cycle (hours UTC) of the summer Urban Heat Island (UHI) in the dense urban environment for different Vegetation scenarios for the period 2010-2040

sub-urban environment for the period 2010-2040. Note that results for the periods 2040-2070 and 20702100 were practically identical. As expected, the largest impact of the albedo increase concerns the daytime UHI as a consequence of the increased incoming radiation. While the maximal UHI reduction in the dense urban environment is $0.46^{\circ} \mathrm{C}$ (dashed orange line), the reduction in the sub-urban areas is $0.55^{\circ} \mathrm{C}$. The difference can be attributed to the dense urban environment where, compared with the sub-urban areas, 1) there is an enhanced heat trapping in the urban canopy and 2) there is more conversion to sensible as opposed to latent heat of the (remaining) incoming radiation.

\section{Scenario impacts on the heat waves}

While, at least in the current model setup, the UHI is not affected by the time period considered, the background temperatures will be steadily increasing with time following the RCP8.5 scenario and reach $3^{\circ} \mathrm{C}$ to $4^{\circ} \mathrm{C}$ at the end of the century. Therefore, as compared to this increase in background temperature, a local reduction of temperature with $0.5^{\circ} \mathrm{C}$ is a minor contribution. This effect can be quantified by the use of the fraction of avoided heat waves upon implementation of a certain adaptation measure. These are shown in Figure 7 for the albedo scenarios (left) and the vegetation scenarios (right). 

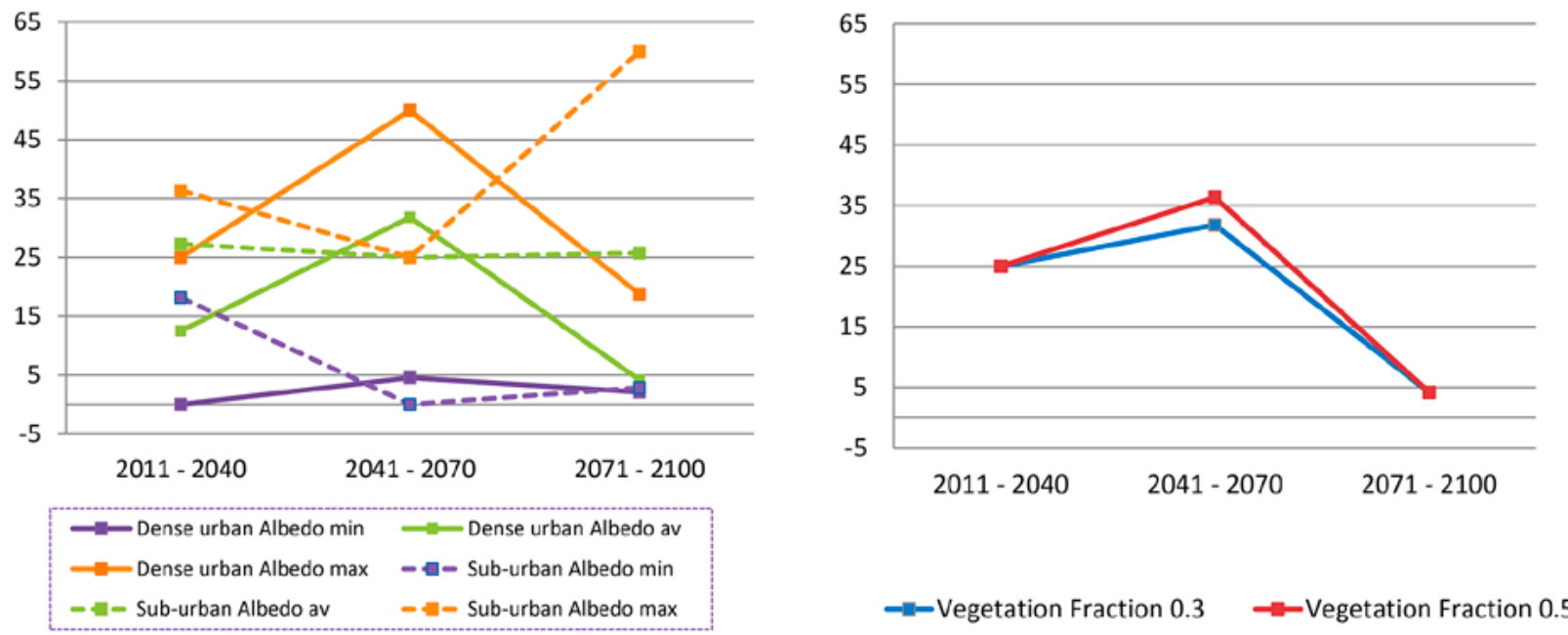

Figure 7. Fraction of avoided heat waves (\%) for different time periods and for different albedo scenarios (left) and vegetation scenarios (right), all following the RCP8.5 scenario

While the fraction of avoided heat waves is up to $35 \%$ for the period 2010-2040 and even up to $50 \%$ for 2040-2070 (both upon following the Albedo max scenario), there seems to be a strong decline for the peri- od 2070-2100, except for the Albedo max scenario in the sub-urban environment. The effect of the vegetation adaptation on the heat wave reduction becomes negligible for the period 2070-2100.

\section{Discussion}

Although an increase in the albedo of streets and walls in an urban environment will generally reduce the UHI effect, it may have detrimental effects on human comfort during day-time. Indeed upon increase of the wall and street albedo a person residing outside will be subject to increased shortwave radiation, thereby strongly affecting the comfort level (Erell et al., 2014). Note that this is not the case for the albedo of the roofs. On the other hand, the day-time outdoor human comfort is generally improved by shading when trees are introduced. The investigation of such effects are important but are beyond the scope of this sensitivity study (Milošević et al, 2017; Di Napoli et al., 2018).

Each scenario had a maximal effect of reducing the UHI by around $0.5^{\circ} \mathrm{C}$. The results of Figs. 5 and 6 show that an albedo increase strongly reduces the day-time UHI, while an increase of the vegetation fraction reduces the night-time UHI. The vegetation scenario can therefore be considered to have the largest impact on health as it allows people in an urban environment to cool down at night.

The current investigation explores the sensitivity of the urban climate with respect to simple land-use change scenarios. However, further in-depth studies are required in order to improve the impact quantification and uncertainty estimation. More specifically, additional analysis should preferably focus on downscaling efforts using data from multiple regional climate models that include atmosphere-city interactions. Nonetheless, the results presented here, although limited in scope, indicate that the integration of adaptation measures by city authorities could lead to substantial reduction of the urban heat island and heat waves that in turn will reduce the climate change impact on the well-being of the urban population. The introduction of green infrastructure provides the most realistic adaptation scenario for sustainable urban development (Rosenzweig et al., 2018).

\section{Conclusions}

Two types of land use scenarios are proposed to investigate the maximal potential on the urban climate in the period 2010-2100 following RCP8.5 for simple adaptation measures for the city of Brussels. Since the urban population mostly suffers from a wide range of impacts during warm and especially heat-wave peri- ods, we focus mostly on the summer period and perform a separate investigation for the impact during heat waves.

First, a change of albedo in urban areas that can be established by a change of the building color, reduces the summer day-time UHI up to $0.5^{\circ} \mathrm{C}$. An increase of 
the vegetation up to $50 \%$ in the dense urban region, on the other hand, reduces the night-time UHI by $0.5^{\circ} \mathrm{C}$. Both were found to be independent on the period considered.

The fraction of avoided heat waves, on the other hand, strongly depends on the climate period. For the peri- ods 2010-2040 and 2040-2070, the reduction can be up to $35 \%$ and $50 \%$ respectively, mostly upon strongly increasing the albedo. However, the fraction of avoided heat waves almost always declines for the period 20702100 (as compared to the 2040-2070 period) due to the overall increase in background temperature.

\section{Acknowledgement}

This work is supported by URCLIM that has received funding from EU's H2O2o Research and Innovation Program under Grant Agreement 690462.

\section{References}

Caluwaerts, S., Hamdi, R., Top, S., Lauwaet, D., Berckmans, J., Degrauwe, D., Dejonghe, H., De Ridder, K., De Troch, R., Duchêne, F., \& Maiheu, B. (2020). The urban climate of Ghent, Belgium: A case study combining a high-accuracy monitoring network with numerical simulations. Urban Climate, 31, 100565. doi: 10.1016/j.uclim.2019.100565

De Munck, C., Lemonsu, A., Masson, V., Le Bras, J., \& Bonhomme, M. (2018). Evaluating the impacts of greening scenarios on thermal comfort and energy and water consumptions for adapting Paris city to climate change. Urban Climate, 23, 260-286. doi: 10.1016/j.uclim.2017.01.003

Di Napoli, C., Pappenberger, F., \& Cloke, H. L. (2018). Assessing heat-related health risk in Europe via the Universal Thermal Climate Index (UTCI). International journal of biometeorology, 62(7), 1155-1165. doi:10.1007/soo484-018-1518-2

Erell, E., Pearlmutter, D., Boneh, D., \& Kutiel, P. B. (2014). Effect of high-albedo materials on pedestrian heat stress in urban street canyons. Urban Climate, 10, 367-386. doi: 10.1016/j.uclim.2013.10.005

Forzieri, G., Cescatti, A., e Silva, F. B., \& Feyen, L. (2017). Increasing risk over time of weather-related hazards to the European population: a data-driven prognostic study. The Lancet Planetary Health, 1(5), e20o-e208. doi: 10.1016/s2542-5196(17)30082-7

Giot, O., Termonia, P., Degrauwe, D., De Troch, R., Caluwaerts, S., Smet, G., Berckmans, J., Deckmyn, A., De Cruz, L., De Meutter, P., Duerinckx, A., Gerard, L., Hamdi, R., Van den Bergh, J., Van Ginderachter, M., \& Van Schaeybroeck, B. (2015). Validation of the ALARO-o model within the EURO-CORDEX framework. Geoscientific Model Development Discussions, 8(10), 8387-8409. doi: 10.5194/gmdd-8-8387-2015

Guerreiro, S. B., Dawson, R. J., Kilsby, C., Lewis, E., \& Ford, A. (2018). Future heat-waves, droughts and floods in 571 European cities. Environmental Re- search Letters, 13(3), 034009. doi: 10.1088/1748-9326/ aaaad $_{3}$

Hamdi, R., Van de Vyver, H., De Troch, R., \& Termonia, P. (2014). Assessment of three dynamical urban climate downscaling methods: Brussels's future urban heat island under an $\mathrm{A} 1 \mathrm{~B}$ emission scenario. International Journal of Climatology, 34(4), 978999. doi: 10.1002/joc.3734

Hamdi, R., Giot, O., De Troch, R., Deckmyn, A., \& Termonia, P. (2015). Future climate of Brussels and Paris for the 2050 s under the A1B scenario. Urban climate, 12, 160-182. doi: 10.1016/j.uclim.2015.03.003 Hamdi, R., Duchêne, F., Berckmans, J., Delcloo, A., Vanpoucke, C., \& Termonia, P. (2016). Evolution of urban heat wave intensity for the Brussels Capital Region in the ARPEGE-Climat A1B scenario. Urban Climate, 17, 176-195. doi: 10.1016/j. uclim.2016.08.001.

Helsen, S., van Lipzig, N. P., Demuzere, M., Broucke, S. V., Caluwaerts, S., De Cruz, L., De Cruz, L., De Troch, R., Hamdi, R., Termonia, P., Van Schaeybroeck, B., \& Wouters, H. (2019). Consistent scaledependency of future increases in hourly extreme precipitation in two convection-permitting climate models. Climate Dynamics, 1-14. doi: 10.1007/ soo382-019-05056-w

Jacob, D., Petersen, J., Eggert, B., Alias, A., Christensen, O. B., Bouwer, L. M., Braun, A., Colette, A., Déqué, M., Georgievski, G., \& Georgopoulou, E. (2014). EURO-CORDEX: new high-resolution climate change projections for European impact research. Regional environmental change, 14(2), 563578. doi: 10.1007/s10113-013-0499-2

Jacob, D., Kotova, L., Teichmann, C., Sobolowski, S. P., Vautard, R., Donnelly, C., Koutroulis, A.G., Grillakis, M.G., Tsanis, I.K., Damm, A., \& Sakalli, A. (2018). Climate impacts in Europe under+ 1.5 C global warming. Earth's Future, 6(2), 264-285. doi: $10.1002 / 2017$ EFooo 710 
Lauwaet, D., De Ridder, K., Saeed, S., Brisson, E., Chatterjee, F., van Lipzig, N. P., Maiheu, B., \& Hooyberghs, H. (2016). Assessing the current and future urban heat island of Brussels. Urban Climate, 15, 1-15. doi: 10.1016/j.uclim.2015.11.008

EEA, F. (2016). Urban sprawl in Europe. Joint EEAFOEN report.

Martinez, G. S., Diaz, J., Hooyberghs, H., Lauwaet, D., De Ridder, K., Linares, C., Carmona, R., Ortiz, C., Kendrovski, V., Aerts, R., \& Van Nieuwenhuyse, A. (2018). Heat and health in Antwerp under climate change: Projected impacts and implications for prevention. Environment international, 111, 135-143. doi: 10.1016/j.envint.2017.11.012

Masson, V. (2000). A physically-based scheme for the urban energy budget in atmospheric models. Boundary-layer meteorology, 94(3), 357-397. doi: 10.1023/A:1002463829265

Masson, V., Champeaux, J. L., Chauvin, F., Meriguet, C., \& Lacaze, R. (2003). A global database of land surface parameters at $1-\mathrm{km}$ resolution in meteorological and climate models. Journal of climate, 16(9), 1261-1282. doi: 10.1175/1520-0442-16.9.1261

Masson, V., Lion, Y., Peter, A., Pigeon, G., Buyck, J., \& Brun, E. (2013). "Grand Paris": regional landscape change to adapt city to climate warming. Climatic Change, 117(4), 769-782. doi: 10.1007/s10584-0120579-1

Masson-Delmotte, V., P. Zhai, H.-O. Pörtner, D. Roberts, J. Skea, P.R. Shukla, A. Pirani, W. MoufoumaOkia, C. Péan, R. Pidcock, S. Connors, J.B.R. Matthews, Y. Chen, X. Zhou, M.I. Gomis, E. Lonnoy, T. Maycock, M. Tignor, \& T. Waterfield (Eds.). (2018). Global Warming of $1.5^{\circ} \mathrm{C}$ : An IPCC Special Report on the Impacts of Global Warming of $1.5^{\circ} \mathrm{C}$ Above Pre-industrial Levels and Related Global Greenhouse Gas Emission Pathways, in the Context of Strengthening the Global Response to the Threat of Climate Change, Sustainable Development, and Efforts to Eradicate Poverty.

Milošević, D. D., Bajšanski, I. V., \& Savić, S. M. (2017). Influence of changing trees locations on thermal comfort on street parking lot and footways. Urban forestry \& urban greening, 23, 113-124. doi: 10.1016/j. ufug.2017.03.011

Oleson, K. W., Bonan, G. B., \& Feddema, J. (2010). Effects of white roofs on urban temperature in a global climate model. Geophysical Research Letters, 37(3). doi: 10.1029/2009GLo42194
Robine, J. M., Cheung, S. L. K., Le Roy, S., Van Oyen, H., Griffiths, C., Michel, J. P., \& Herrmann, F. R. (2008). Death toll exceeded 70,000 in Europe during the summer of 2003. Comptes rendus biologies, 331(2), 171-178. doi: 10.1016/j.crvi.2007.12.001

Rosenzweig, C., Solecki, W. D., Romero-Lankao, P., Mehrotra, S., Dhakal, S., \& Ibrahim, S. A. (Eds.). (2018). Climate change and cities: Second assessment report of the urban climate change research network. Cambridge University Press. doi: 10.1017/9781316563878.007

Termonia, P., Fischer, C., Bazile, E., Bouyssel, F., Brožková, R., Bénard, P., Bochenek, B., Degrauwe, D., Derková, M., El Khatib, R., \& Hamdi, R. (2018a). The ALADIN System and its canonical model configurations AROME CY41T1 and ALARO CY40T1. Geoscientific Model Development, 11, 257-281.

Termonia, P., Van Schaeybroeck, B., De Cruz, L., De Troch, R., Caluwaerts, S., Giot, O., Hamdi, R., Vannitsem, S., Duchêne, F., Willems, P. \& Tabari, H. (2018b). The CORDEX. be initiative as a foundation for climate services in Belgium. Climate Services, 11, 49-61. doi: 10.1016/j.cliser.2018.05.001

Termonia, P., Van Schaeybroeck, B., De Cruz, L., De Troch, R., Giot, O., Hamdi, R., Vannitsem, S., Duchêne, F., Willems, P., Tabari, H., \& Van Uytven, E. (2018c). Combining regional downscaling expertise in Belgium: CORDEX and beyond (No. Final report-BR/143/A2/CORDEX. be). Politique Scientifique Fédérale (Belgique) [Belgian Federal Science Policy].

Top, S., Caluwaerts, S., Van Schaeybroeck, B., Hamdi, R., Duchêne, F., \& Termonia, P. (2019). Modelling the urban heat island: sensitivity to land cover data. In 2019 Joint Urban Remote Sensing Event (JURSE) (pp. 1-4). IEEE. 10.1109/JURSE.2019.8809032

Wouters, H., De Ridder, K., Poelmans, L., Willems, P., Brouwers, J., Hosseinzadehtalaei, P., Tabari, H., Broucke, S.V., van Lipzig, N.P.\& Demuzere, M. (2017). Heat stress increase under climate change twice as large in cities as in rural areas: A study for a densely populated midlatitude maritime region. Geophysical Research Letters, 44(17), 89979007.doi: 10.1002/2017GL074889

Zhou, Y., \& Shepherd, J. M. (2010). Atlanta's urban heat island under extreme heat conditions and potential mitigation strategies. Natural Hazards, 52(3), 639668. http://dx.doi.org/10.1007/s11069-009-9406-z. 